\title{
Gold Plating in the Electronics Industry
}

\author{
CURRENT TRENDS REPORTED AT A RECENT CONFERENGE
}

\author{
J. W. Dini \\ Sandia Laboratories, Livermore, CA., U.S.A.
}

The central theme of most of the papers on gold plating at the 1979 American Electroplaters' Society conference was that of reducing gold costs. Selective plating, use of dilute electrolytes or electroless gold solutions and reduction of thickness of electrolytic deposits were suggested as effective means of minimizing costs.

\section{Selective Plating}

The three types of reel-to-reel machines most often encountered for selective plating in the electronics industry are engineered to produce controlled depth, stripe, and spot plating respectively. With controlled depth plating, deposition of gold is performed at current densities in the range of 250 to $1000 \mathrm{~A} / \mathrm{m}^{2}$, near an edge of the strip which is partially immersed in the electrolyte. For stripe plating, whereby thin stripes of gold are deposited on strips of metallic substrate suitably masked so that only the selected area is subjected to plating, current densities vary from 1000 to $5000 \mathrm{~A} / \mathrm{m}^{2}$. The highest plating speeds are achieved in equipment designed for spot plating gold onto strips at current densities of 5000 to $25000 \mathrm{~A} / \mathrm{m}^{2}$. Plating solutions for these applications, as discussed by F. I. Nobel and D. W. Thompson of Lea Ronal, Inc., Freeport, New York, must be tailor-made for each particular type of machine so that the deposit meets the required metallurgical characteristics. For deposits used in the alloying, bonding and sealing operations performed in semiconductor manufacturing, the authors suggested categorizing solutions into three operating current density ranges $(10000$ to 20000,3000 to 10000 and 100 to $\left.300 \mathrm{~A} / \mathrm{m}^{2}\right)$. Solu- tions for the upper range have high metal concentration and can readily deposit gold at the rate of $1 \mu \mathrm{m} / \mathrm{s}$ at 70 to $80^{\circ} \mathrm{C}$. In the middle range, care must be taken to avoid co-deposition of metallic contaminants with the gold. This is achieved by use of bath formulations which are less aggressive to the substrate metal or alloy or by use of chelating agents. For the lower current density range, electrolyte formulations are similar to those used in rack plating. Where coatings with good wear resistance are required, many successful reel-to-reel plating installations are available for depositing cobalt-hardened gold at current densities up to $6000 \mathrm{~A} / \mathrm{m}^{2}$. In these installations the baths typically require higher gold concentrations and operating conditions must be such as to prevent development of high concentrations of cyanide, which can form complexes with the cobalt and prevent it from co-depositing. This is achieved by use of higher temperatures, higher agitation, lower $\mathrm{pH}$ and more effective chelating agents, together with lower total amperage per unit volume of bath.

A drawback of cobalt- or nickel-hardened golds is the gradual increase in contact resistance which occurs after long term exposure of these deposits to elevated temperatures. A cadmium-hardened gold, capable of being plated in reel-to-reel equipment is superior to cobalt-hardened golds in this respect. An added advantage is that the gold-cadmium solution is not affected by cyanide and will remain stable even under the adverse conditions of high total current per volume unit of solution. In forming applications for which conventional cobalt- and nickel-hardened golds are too brittle, a pure hard gold bath can be adapted for high speed reel-to-reel plating at current densities as high as $5000 \mathrm{~A} / \mathrm{m}^{2}$.

D. W. Endicott and G. J. Casey, Jr., of Motorola, Inc., Phoenix, Arizona, reported on the development of dilute electrolytes for high speed gold plating, to minimize the problems of high inventory values and drag-out losses. Deposits had to be satisfactory for fast die attach and thermal compression wire bond assembly techniques while capable of being plated at a minimum strip speed of $150 \mathrm{~mm} / \mathrm{s}$. A commercial machine which utilized a moving mask was chosen for the work. The coating sequence consisted of a nickel sulfamate strike followed by $0.125 \mu \mathrm{m}$ of gold on both sides of the lead frame from an electrolyte 
with $4 \mathrm{~g} / 1$ gold and a final selective gold deposit $1 \mu \mathrm{m}$ thick from a $9 \mathrm{~g} / 1$ gold solution. In the testing programme, it was found that both die and wire bond pull test failures were associated with the nickel underlayer. Copper contamination of the nickel sulfamate solution, contamination of the surface of the nickel and oxide formation before gold striking caused die bond failures. Electrolytic purification to reduce the copper level in the nickel solution to less than 3 ppm, carbon treatment every 5 working days and rinsing the nickel deposit in the acid associated with the gold electrolyte eliminated these problems. The major contaminant causing wire bond failures was diffused nickel and above 3 atomic per cent of that element on the surface of the gold caused rejects.

\section{Process Control}

In a subsequent paper, the above authors reported on the use of Auger Electron Spectroscopy (AES) as a process control tool to determine the effects on the properties of deposits of changes in bath composition and operating conditions. The good reproducibility of the AES data made it possible to optimize the concentration of chelating agents, which could not be done from wire bond tests alone.

B. Sewell of Twickenham Plating and Enamelling Co. Ltd., Twickenham, England, defined contamination as the presence of a chemical element or compound in the plating bath not by design or original formula specification. Contaminants in hard acid gold baths can affect the wear resistance and ductility of deposits from them, while if present in pure gold baths they can degrade die and wire bonding properties of the deposits. Many systems for high speed selective plating are conducive to very rapid contamination of gold electrolytes because unplated surfaces of components contact the electrolyte in low potential areas and during inter-cycle periods. Since removal of contaminants is difficult and preventing their recurrence is problematic, the author recommended a policy of contaminant control. By regular replacement of a part of the production bath with new clean electrolyte, a balance can be maintained between electrolyte composition and contaminant concentration. Replacement can be effected with advantage by production of fresh $\mathrm{KAu}(\mathrm{CN})_{2}$ from discarded electrolyte. This is done by plating the gold from it onto a cathode and then using this cathode in a conversion cell to produce crystals of $\mathrm{KAu}(\mathrm{CN})_{2}$ which, in turn, can be added to the original plating solution. A membrane such as a porous pot is used in the conversion cell which contains $\mathrm{KCN}$ as the anolyte and $\mathrm{KOH}$ as the catholyte. Many kilograms of gold may be processed through 1 litre of electrolyte with a yield better than 99.9 per cent before it becomes necessary to provide fresh anolyte.

\section{Properties and Performance of Coatings}

In an excellent objective review of the various methods for measuring deposit thickness, I. Cross of Harper-Leader, Inc., Waterbury, Connecticut, stressed the importance of knowing the actual density of the coating being measured. Because of significant variables in the plating process, the density of socalled 'pure' gold can range from the theoretical 19.3 down to $15.7 \mathrm{~g} / \mathrm{cm}^{3}$. To avoid erroneous readings with any method that converts mass per unit area to thickness, extreme care must be taken to ensure that the standards used for calibration are of a precisely known density.

W. G. Bader, of Bell Laboratories in Murray Hill, New Jersey, discussed the effects of storage for 23 years on the solderability of electrodeposited gold coatings. He concluded that for parts stored at $27^{\circ} \mathrm{C}$, long term solderability can be retained with $0.75 \mu \mathrm{m}$ of gold over copper, nickel, nickel-silver or phosphor bronze. With brass, a $2.5 \mu \mathrm{m}$ nickel undercoat is recommended under $0.75 \mu \mathrm{m}$ of gold.

\section{Non-Conventional Plating Techniques}

In order to plate the successive layers of copper, nickel and gold which form the conductive paths on bi-level film integrated circuits used for telephone electronic switching applications, L. M. Georgiev, R. J. Ozga and R. Chmielewski of Western Electric Co. in Chicago, Illinois, used a technique referred to as 'box' plating. With this approach, gold usage is reduced by 75 per cent. Other advantages include faster plating rates, improved thickness uniformity and compact plating equipment. The fixtures are basically slotted bottomless boxes made of PVC, CPVC, or polypropylene with stainless steel anode and cathode bus bars. Thirteen anodes are positioned in alternate slots permitting 12 substrates to be coated front and back simultaneously. Pulse plating is used for frontside copper and gold while direct current is used for nickel and all backside plating. When pulse plating is used, deposition times are reduced by 30 per cent as higher current densities are allowable.

C. J. Stimetz of Bendix Corp., Kansas City, Missouri, and J. J. Hren of Materials Consultants, Gainesville, Florida, reported on features of cobalthardened gold deposited by pulse plating (see Gold Bulletin, 1979, 12, (3), 114-115).

Work on electroless and immersion golds was reported by R. K. Asher of Motorola, Inc, Phoenix, Arizona. His results will be detailed in the next issue of Gold Bulletin.

Sur/Fin 79 maintained the high standard of these annual conferences of the American Electroplaters' Society which are now widely accepted as a forum for the disclosure and discussion of developments in the field of gold electrodeposition. 